\title{
Comparison of glycaemic control and anthropometric parameters before and after Ramadan fasting in a selected cohort of patients with type 2 diabetes mellitus in Sri Lanka
}

\author{
Mohamed Shafras ${ }^{182}$, Lakshika Monaragala², Isha Samarakkody ${ }^{2}$, Rafeek Rukshan Ahamed ${ }^{2}$, \\ Lakshika Nawarathna ${ }^{3}$, Mohamed Sanas ${ }^{2}$, Charles Antonypillai ${ }^{2}$
}

(Index words: ramadan fasting, diabetes mellitus, glycaemic control, fructosamine)

\begin{abstract}
Introduction The majority of Sri Lankan Moors fast during Ramadan. This may have an effect on their glycaemic control and anthropometric parameters. However, limited information exists about the impact of Ramadan fasting on diabetes in Sri Lanka.

Objectives The main objective of this study was to investigate the effect of Ramadan fasting on glycaemic control and anthropometric parameters in patients with type 2 diabetes mellitus (T2DM). Patients were also observed for symptoms of hypoglycaemia, timing and association with different antidiabetic agents.

Methods One hundred and twenty Sri Lankan Moors with T2DM were recruited for this study. Biochemical investigations and collection of anthropometric parameters were performed before and after Ramadan fasting. The statistical analysis was done with paired $t$ test to compare glycaemic control and anthropometric parameters before and after Ramadan.

Results There was a significant decrease in body weight (mean body weight 66.17 to $65.52 \mathrm{~kg} ; \mathrm{p}=<0.001$ ) and waist circumference (93.84 to $92.16 \mathrm{~cm} ; \mathrm{p}=<0.001)$. However, the glycaemic control worsened in all patients during Ramadan with rise in mean fructosamine value of 354.1 to $996.9 \mu \mathrm{mol} / \mathrm{L}$. Out of 104 participants 43 participants experienced symptoms of hypoglycaemia.

Conclusions The current study showed an improvement in the body weight and waist circumference during Ramadan fasting, however the glycaemic control has been worsened. More follow-up studies are warranted in order to draw a conclusion on the effect of Ramadan fasting in glycaemic control and anthropometric parameters in diabetes patients.
\end{abstract}

Ceylon Medical Journal 2020; 65: 79-85

DOI: http://doi.org/10.4038/cmj.v65i4.9276

\section{Introduction}

Fasting during the holy month of Ramadan is an obligatory duty for all healthy adult Muslims. Whereby, they abstain from the uptake of food, drink or oral medicines from sunrise to sunset throughout the month of Ramadan [1]. The number of days in this month varies from 29-30. Thus, the total number of fasting days also changes from year to year.

According to the World Health Organization (WHO) reports the number of diabetes mellitus patients (DM) has increased from 108 to 422 million from 1980-2014, in which adults over 18 years of age has risen from $4.7 \%$ to $8.5 \%$ [2]. Based on a demographic study conducted in 2010, approximately 1.6 billion (23\%) of the worldwide population are followers of Islam [3], of which 40-50 million individuals with diabetes fast during the month of Ramadan [4]. A population based study on the epidemiology of diabetes and Ramadan (EPIDIAR) indicated that $42.8 \%$ of patients with type 1 and $78.7 \%$ of those with T2DM patients fasted during Ramadan [5]. Ramadan fasting entails major changes in dietary patterns which leads to metabolic alterations in both healthy and individuals with any medical condition [6, 7]. Despite taking fewer meals, this practice is usually compensated by ingesting large amounts of sugary food and drinks that are high in carbohydrates and fats, especially during the breaking of fasting [8]. The overall calorie consumption of individuals with T2DM has been reported to increase during Ramadan $[9,10]$.

During Ramadan, it has also been reported that physical activities, especially exercising, and other regular day-to-day activities tend to decrease due to fear of feeling too weak [11]. However, studies have shown that light to moderate exercise has no serious effects on individuals with T2DM [12]. Many studies have been conducted in

${ }^{1}$ Postgraduate Institute of Science, University of Peradeniya, Sri Lanka, ${ }^{2}$ Department of Diabetes and Endocrinology, National Hospital, Kandy, Sri Lanka, ${ }^{3}$ Department of Statistics and Computer Science, University of Peradeniya, Sri Lanka.

Correspondence: MS, e-mail: <way2shafraz@gmail.com >. Received 20 April 2020 and revised version 20 November 2020 accepted 02 December 2020.

This is an open-access article distributed under the terms of the Creative Commons Attribution License, which permits unrestricted use, distribution, and reproduction in any medium, provided the original author and source are credited. 
other Asian [13-15] and Middle Eastern countries [16-18] targeting fasting patients with diabetes, but up to our knowledge there are no published studies in Sri Lanka. Therefore, the objective of this study is to determine the effect of Ramadan fasting on glycaemic control and anthropometric parameters in a selected cohort of patients with T2DM in Sri Lanka.

\section{Materials and methods}

This is a prospective cross-sectional study conducted from May to July 2016 among a group of Sri Lankan Moors with T2DM attending the Diabetic Clinic, National Hospital, Kandy, Sri Lanka. Ethical clearance was obtained from Ethics Review Committee of National Hospital, Kandy. All the protocols used were in accordance with the guidelines for the protection of human subjects. American Diabetes Association (ADA) guidelines were used for diagnosis of DM [19]. Sri Lankan Moors with T2DM and who were planning to fast for more than 25 days were enrolled to the study after obtaining the written consent. Patients hospitalized for diabetic ketoacidosis or hypoglycaemia a month prior to Ramadan fasting and patients receiving or had received short term corticosteroid therapy a month prior to Ramadan fasting were excluded. Participants were instructed about change in drug dose and requested to adhere to it during Ramadan.

The total number of fasting days in the month of Ramadan in 2016 was 30 days (6 June - 5 July 2016). Demographic characteristics, medical and social histories were obtained with the use of standardized questionnaires by interviewing participants before and after Ramadan fasting.

\section{Anthropometric parameters}

Body weight, height and waist circumferences were measured one week before and after Ramadan fasting using the same calibrated instruments. Body mass index (BMI) was calculated for all participants. Venous blood sample was collected from all participants one week prior and one week after Ramadan fasting to measure serum glycated proteins. Serum glycated proteins, measured as fructosamine, is used as an alternative assay to measure glycaemic control over a shorter duration. Most of the serum fructosamine is represented by glycated albumin which has a half-life of approximately 20 days, hence could be a better marker to monitor metabolic alterations occurring within one month [20]. Fructosamine was assessed using Analyzer A25 instrument (BioSystems S.A. Costa Brava 30, 08030 Barcelona Spain). The Minitab statistical software (Version 17) was used for the entire analysis. The paired t-test was carried out in order to find out the relationship between following variables (fructosamine level before and after Ramadan, weight before and after Ramadan and waist circumferences before and after Ramadan) and p value $<0.05$ was considered as statistically significant.

\section{Hypoglycaemic events}

Participants were advised about the symptoms of hypoglycaemia and possibility of experiencing hypoglycaemia during Ramadan. Patients were also instructed on the management of such a situation and requested to note down the symptoms of hypoglycaemia, frequency, and time that they experienced the symptoms. All participants were contacted through phone calls weekly to record the hypoglycaemic events, symptoms and the timing of events.

\section{Drug management}

According to the ADA guidelines 2010 patients were prescribed half of their routine night dose to be taken during early morning before fasting (sahur) and routine morning dose was prescribed to be taken after breaking the fast (iftar) by the clinicians [21].

\section{Results}

Based on the inclusion and exclusion criteria, 120 patients were recruited for the study. Of the 120 patients, 104 patients completed the study and the remaining patients fasted for less than 25 days. Patients enrolled in the study had a history of DM ranging from one month to 30 years and more than $34 \%$ of the patients living with DM for more than 10 years (Table 1 ). The mean ages of the male and female populations were found to be 58 years (range 42-80) and 54 years (range 35-76) respectively.

After one month of fasting, 72 patients had been reduced body weight and 30 patients showed an increase in body weight whereas 2 patients showed no change in body weight. It was also observed that the waist circumference had been reduced in 64 patients and 21 patients showed increase in waist circumference while 19 patients showed no change in waist circumference after one month of fasting. All 104 patients showed a significant increase in fructosamine level after one month of fasting $(p<0.001)$. Mean fructosamine level and the range before and after Ramadan was $354.1 \mu \mathrm{mol} / \mathrm{L}$ (223 - $506 \mu \mathrm{mol} / \mathrm{L}$ ) and $996.9 \mu \mathrm{mol} / \mathrm{L}$ (604 - $1678 \mu \mathrm{mol} / \mathrm{L}$ ) respectively. The mean initial HbA1c of this population was found to be $9.88 \%$. Anthropometric and glycaemic changes before and after Ramadan fasting is shown in Table 2.

The effect of Ramadan fasting on weight change among patients of different classes of BMI were analysed (Table 3). Patients were classified according to the BMI categories based on the weight and height obtained prior to fasting. The current study showed that 36 patients were under the normal BMI range whereas the majority of patients $(n=45)$ were overweight. The study population also had 22 obese patients and one patient was found to be underweight. All BMI categories showed statistically significant weight reduction except for the low BMI category (Figure 1). Rate of weight reduction was high among patients with higher BMI. The current study 
showed significant reduction in waist circumference after Ramadan fasting. Collectively the anthropometric parameters have been improved in the current study population after Ramadan fasting.

Table 1. Demographic characteristics of the patients

\begin{tabular}{llll}
\hline & Category & Count & Percentage (\%) \\
\hline Sex & Female & 64 & 61.5 \\
Male & Divorced & 40 & 38.5 \\
Marital status & Married & 2 & 1.9 \\
& Single & 86 & 82.7 \\
& Widowed & 1.0 & 14.4 \\
Education & Uneducated & 15 & 1.0 \\
& Primary School & 1 & 14.4 \\
& High School & 15 & 83.6 \\
Erequency of exercising & University & 87 & 1.0 \\
& Never & 1 & 90.4 \\
& $1-2$ times a week & 94 & 1.9 \\
& $2-4$ times a week & 2 & 1.0 \\
Following a diet plan/not & 5-6 times a week & 1 & 2.9 \\
& Yes & 3 & 3.8 \\
& No, aware of food affecting & 4 & 24.0 \\
glycaemic control & & 43.3
\end{tabular}

Table 2. Anthropometric and glycaemic changes before and after Ramadan fasting $(n=104)$

\begin{tabular}{lccc}
\hline Characteristics & Mean difference & Paired t-test statistic & $p$-value \\
\hline Weight $(\mathrm{kg})$ & $0.7 \pm 1.1$ & 5.6 & $<0.001$ \\
Waist circumference $(\mathrm{cm})$ & $1.7 \pm 3.2$ & 5.4 & $<0.001$ \\
Fructosamine $(\mu \mathrm{mol} / \mathrm{L})$ & $-642.8 \pm 190.9$ & -34.3 & $<0.001$ \\
\hline
\end{tabular}

Table 3. Analysis for different BMI classes

\begin{tabular}{llccc}
\hline $\begin{array}{c}\text { BMI group } \\
k g / m^{2}\end{array}$ & $n$ & $\begin{array}{c}\text { Before } \\
\text { Mean } \pm S D\end{array}$ & $\begin{array}{c}\text { After } \\
\text { Mean } \pm S D\end{array}$ & $\begin{array}{c}\text { Paired statistic } \\
t \text {-test }\end{array}$ \\
\hline Under weight (<18.5) & 1 & - & - \\
Normal (18.5-24.9) & 36 & $55.4 \pm 6.0$ & $55.0 \pm 6.1$ & 2.4 \\
Overweight (25.0-29.9) & 45 & $67.3 \pm 7.0$ & $66.6 \pm 7.2$ & 3.4 \\
Obese class 1 (30.0-34.9) & 16 & $79.8 \pm 8.6$ & $78.8 \pm 8.5$ & 3.4 \\
Obese class 2 (35.0-39.9) & 6 & $89.5 \pm 6.1$ & $88.4 \pm 5.5$ & 0.001 \\
\hline
\end{tabular}




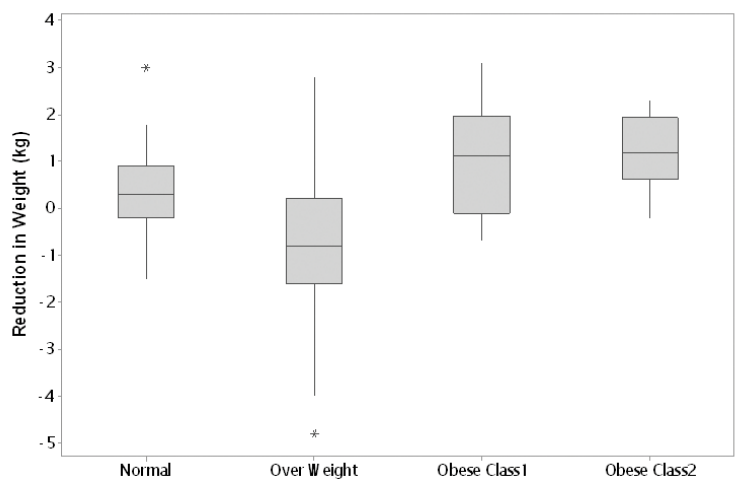

Figure 1. Boxplot diagram showing weight reduction among different $\mathrm{BMI}$ categories.

Out of 104 participants 43 participants experienced symptoms of hypoglycaemia at least once during the period of Ramadan and one patient experienced severe hypoglycaemia which necessitated hospital admission. Moreover, 2 patients had symptoms of hypoglycaemia for 30 days during the fasting time. Most of the participants experienced symptoms of hypoglycaemia between 12:00 18:00. Figure 2 describes the hypoglycaemic events and the onset time.

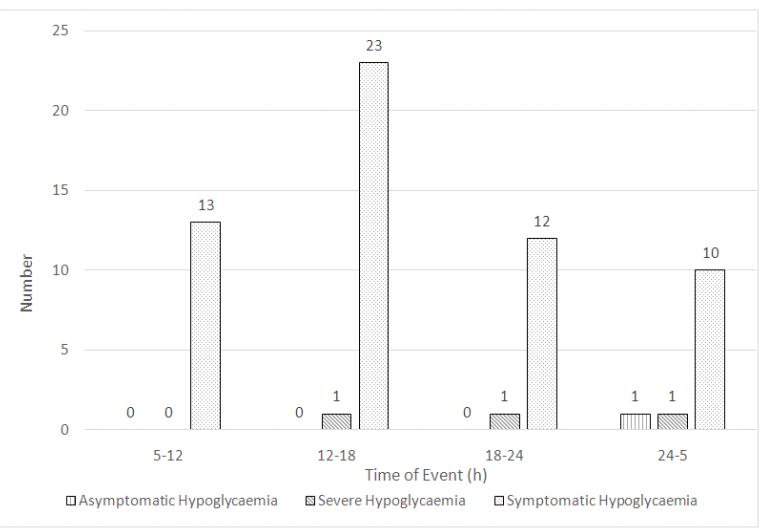

Figure 2. Hypoglycaemic events and onset time.

Asymptomatic hypoglycaemia - patient regularly checks his blood glucose level using his own glucometer and in one occasion his value was found to be $55 \mathrm{mg} / \mathrm{dl}$.

Severe hypoglycaemia - patient required hospital admission and blood glucose levels biochemically proven.

Symptomatic hypoglycaemia - patients experienced symptoms of hypoglycaemia although they have not measured their blood glucose levels with glucometers.

Patients were also categorised based on their medication to observe the effect of different drug categories on symptoms of hypoglycaemia. Number of symptoms of hypoglycaemia for different drug groups is shown in
Table 4. The study showed that patients using sulphonylurea drugs experienced highest number of symptoms of hypoglycaemia.

Table 4. Different drug categories and symptoms of hypoglycaemia

\begin{tabular}{ccc}
\hline Category & $\begin{array}{c}\text { Number of patients } \\
\text { experienced symptoms } \\
\text { of hypoglycaemia }\end{array}$ & percentage \\
\hline G1 & 6 & 13.6 \\
G2 & 16 & 36.4 \\
G3 & 6 & 13.6 \\
G4 & 16 & 36.4 \\
\hline
\end{tabular}

G1= No insulin or sulphonylurea (only metformin/acarbose/ sitagliptin)

G2 = Sulphonylurea and no insulin

G3 = Insulin and no sulphonylurea

G4 = Insulin and sulphonylurea

\section{Discussion}

The changes in the lifestyle during the holy month of Ramadan causes many negative impacts on patients with T2DM including derangement of glycaemic control, either hypoglycaemia or hyperglycaemia and metabolic emergencies, such as diabetic ketoacidosis, dehydration, renal impairment and hypotension [22]. This study focused on the effect of Ramadan fasting on glycaemic control and anthropometric parameters in T2DM patients. In agreement with previous studies [16, 23] our study also showed a decrease in body weight $(\mathrm{p}<0.001)$ and waist circumference $(p<0.001)$. Studies on healthy individuals showed reduction in body weight after one month of Ramadan fasting [24-26]. However, contradictory results were observed in diabetic patients. Studies on diabetic patients who fast during Ramadan showed an increase in body weight $[27,28]$, no change $[17,29]$ and decrease $[16$, 23] in body weight.

Several studies have investigated the effect of Ramadan fasting on glycaemic control in normal and diabetes patients. Based on the glycaemic marker fructosamine, our study showed significant increase in fructosamine levels $(\mathrm{p}<0.001)$ before and after Ramadan fasting. However, previous studies by Mafauzy et al and Gustaviani et al in Malaysia and Indonesia showed that the fructosamine values reduced after one month of Ramadan fasting [15, 30]. The increase in fructosamine after Ramadan fasting may be due to the changes in food pattern including consumption of large amount of starchy foods during sahur and dates and rice porridge (has a high glycaemic index $78 \pm 9$ ) during iftar. Furthermore altered regular physical activities and exercising patterns 
during Ramadan period due to fear of hypoglycaemia may have increased the fructosamine levels. Moreover the reduction in routine antidiabetic drug doses may also have a negative impact on the glycaemic control.

All BMI categories showed statistically significant weight reduction except the low BMI category. Rate of weight reduction was high among patients with higher BMI. Although it was not statistically significant there was a positive association between weight reduction and BMI categories. The weight and waist circumference reduction in our study may be due to the physiological effect of fasting which is known as catabolic phase of the metabolism. Fasting reduces the blood glucose level and to maintain the homeostasis the body replaces the glucose by gluconeogenesis, which ultimately results in lipolysis. Continuous lipolysis can result in reduction of weight and waist circumference.

A study conducted by Sahin et al in 2013 showed both severe hyperglycaemia and hypoglycaemia were higher in the fasting group [31]. In the present study symptoms of hypoglycaemia was reported in more than $40 \%$ of the T2DM patients and one patient among them required hospital admission due to severe hypoglycaemia. The EPIDIAR study found that the change in eating patterns during Ramadan increased the risk of severe hypoglycaemia by 7.5-fold and severe hyperglycaemia by 5-fold in T2DM [5]. Symptoms of hypoglycaemia is more commonly (72.7\%) observed in patients on sulphonylurea drugs compared to those who were not on sulphonylureas (27.2\%). This is expected as sulphonylurea drugs are secretagogues and are known to cause hypoglycaemia [32]. This can be overcome to a certain extent by changing long acting sulphonylureas such as glibenclamide, to second-generation sulphonylureas like gliclazide, glipizide or glimepiride that are less associated with hypoglycaemia [33].

\section{Conclusion}

In conclusion diabetes patients showed an improvement in anthropometric parameters after Ramadan fasting. However, there was a worsening of glycaemic control in all the patients due to the changes in lifestyle, fasting hours, food consumption, food composition and the quantum of exercise during the month of Ramadan. As most of the Sri Lankan Moors with and without any medical condition fast during the month of Ramadan, it is essential to understand the biochemical and physiological effect of Ramadan fasting in patients with diabetes. Therefore, drug dosage adjustments should be individualized for each patient with diabetes who is willing to fast during Ramadan and glycaemic control should be closely monitored. This study was done at a single centre with a small sample size. Therefore, our study cannot be generalised, and thus more experimental studies are required to observe the relationship between Ramadan fasting and glycaemic control and anthropometric parameters.

\section{Strengths and limitations of this study}

This is one of the first few studies done in these parts of the world in patients with Ramadan fasting. This will provide insight to physicians on diabetes and Ramadan fasting. There were few limitations in our study. The reason for not fasting for more than 25 days was not evaluated. Hypoglycaemia was not biochemically proven for all the participants as only few participants had their own glucometers and thus only symptoms of hypoglycaemia was recorded for the participants.

\section{Acknowledgements}

The authors acknowledge Prof. H.K.I. Perera of the Department of Biochemistry, Faculty of Medicine, University of Peradeniya, Peradeniya, Sri Lanka for her assistance in compiling the manuscript. The authors also acknowledge all the staff members of Department of Diabetes and Endocrinology, National Hospital, Kandy, Sri Lanka for the assistance in the smooth conduct of the study.

A part of the results of this research has been published as an abstract in Kandy Society of Medicine (KSM) annual academic session 2018.

\section{Conflicts of interest}

The authors declare that there is no conflict of interest regarding the publication of this paper.

\section{Funding}

This research did not receive any specific grant from any funding agency in the public, commercial or not-forprofit sector.

\section{Data availability}

The data (biochemical investigations, anthropometric parameters and statistical analysis) used to support the findings of this study are available from the corresponding author upon request.

\section{Compliance with ethical standards \\ Ethical approval}

All procedures performed in studies involving human participants were in accordance with the ethical standards of the Ethical Review Committee of National Hospital, Kandy, Sri Lanka.

\section{References}

1. Trepanowski JF, Bloomer RJ. The impact of religious fasting on human health. Nutr J 2010; 9: 57. doi:10.1186/ 1475-2891-9-57.

2. World Health Organization. Global Report on Diabetes. 
WHO Press, 2016. http://apps.who.int/iris/bitstream/ handle/10665/204871/9789241565257_eng.pdf;jsessi onid=D632B8E2BFBCA19DCB671E44B3D34FDE? sequence $=1$ (Accessed on July 30 2019)

3. The Future of the Global Muslim Population. Pew Research Center. 2011. Accessed July 30 2019. http://www. factbook.net/muslim_pop.php (Accessed on July 30 2019).

4. Al-Arouj M, Assaad-Khalil S, Buse J, et al. Recommendations for management of diabetes during Ramadan: update 2010. Diabetes Care 2010; 33(8): 1895-902. doi:10.2337/dc10-0896.

5. Salti I, Benard E, Detournay B, et al. A population-based study of diabetes and its characteristics during the fasting month of Ramadan in 13 countries: results of the epidemiology of diabetes and Ramadan 1422/2001 (EPIDIAR) study. Diabetes Care 2004; 27(10): 2306-11. doi:10.2337/diacare.27.10.2306.

6. Siaw MY, Chew DE, Dalan R, et al. Evaluating the Effect of Ramadan Fasting on Muslim Patients with Diabetes in relation to Use of Medication and Lifestyle Patterns: A Prospective Study. Int J Endocrinol 2014; 2014: 308546. doi:10.1155/2014/308546.

7. M’Guil M, Ragala MA, El Guessabi L, et al. Is Ramadan fasting safe in type 2 diabetic patients in view of the lack of significant effect of fasting on clinical and biochemical parameters, blood pressure, and glycemic control? Clin Exp Hypertens 2008; 30(5):339-57.

doi:10.1080/10641960802272442.

8. Benaji B, Mounib N, Roky R, et al. Diabetes and Ramadan: review of the literature. Diabetes Res Clin Pract 2006;73(2):117-25. doi:10.1016/j.diabres.2005.10.028.

9. Vasan SK, Karol R, Mahendri NV, Arulappan N, Jacob JJ, Thomas N. A prospective assessment of dietary patterns in Muslim subjects with type 2 diabetes who undertake fasting during Ramadan. Indian J Endocrinol Metab 2012; 16(4):552-7. doi:10.4103/2230-8210.98009.

10. Khaled BM, Belbraouet S. Effect of Ramadan fasting on anthropometric parameters and food consumption in 276 type 2 diabetic obese women. Int J Diabetes Dev Ctries 2009; 29(2): 62-8. doi:10.4103/0973-3930.53122.

11. McNeil J, Mamlouk MM, Duval K, Schwartz A, Nardo Junior N, Doucet E. Alterations in metabolic profile occur in normal-weight and obese men during the Ramadan fast despite no changes in anthropometry. J Obes. 2014; 2014: 482547. doi:10.1155/2014/482547.

12. Ewis AN, editor. Ramadan fasting and non-insulindependent diabetes mellitus: Effect of regular exercice. The Second International Congress on Ramadan and Health; 1997; Istanbul, Turkey.

13. Mafauzy M. Repaglinide versus glibenclamide treatment of Type 2 diabetes during Ramadan fasting. Diabetes Res Clin Pract 2002; 58(1): 45-53. doi:10.1016/s01688227(02)00104-3.

14. Chandalia H, Bhargav A, Kataria V. Dietary pattern during
Ramadan fasting and its effect on the metabolic control of diabetes. Pract. Diabetes 1987; 4(6): 287-90.

15. Gustaviani R, Soewondo P, Semiardji G, Sudoyo AW. The influence of calorie restriction during the Ramadan fast on serum fructosamine and the formation of beta hydroxybutirate in type 2 diabetes mellitus patients. Acta Med Indones 2004; 36(3): 136-41.

16. Khatib FA, Shafagoj YA. Metabolic alterations as a result of Ramadan fasting in non-insulin-dependent diabetes mellitus patients in relation to food intake. Saudi Med J 2004; 25(12): 1858-63.

17. Sulimani RA, Laajam M, Al-Attas $\mathrm{O}$, et al. The effect of Ramadan fasting on diabetes control in type II diabetic patients. Nutr Res 1991; 11(2-3): 261-4.

18. Yarahmadi S, Larijani B, Bastanhagh M, et al. Metabolic and clinical effects of Ramadan fasting in patients with type II diabetes. Journal of the College of Physicians and Surgeons - Pakistan: J Coll Physicians Surge Pak 2003; 13(6): 329-32.

19. Standards of medical care in diabetes - 2011. Diabetes Care 2011; 34 Suppl 1:S11-61. doi:10.2337/dc11-S011.

20. Al-Hader AFA, Abu-Farsakh NA, Khatib SY, Hasan ZA. The effects of Ramadan fasting on certain biochemical parameters in normal subjects and in type II diabetic patients. Ann Saudi Med 1994; 14(2): 139-41.

21. Standards of medical care in diabetes - 2010. Diabetes Care 2010; 33 Suppl 1: S11-61. doi:10.2337/dc10-S011.

22. Ahmed SH, Chowdhury TA, Hussain S, et al. Ramadan and Diabetes: A Narrative Review and Practice Update. Diabetes Ther 2020; 11:2477-2520. https://doi.org/10.1007/ s13300-020-00886-y

23. Bravis V, Hui E, Salih S, Mehar S, Hassanein M, Devendra D. Ramadan Education and Awareness in Diabetes (READ) programme for Muslims with Type 2 diabetes who fast during Ramadan. Diabet Med 2010; 27(3): 327-31.

24. Azizi F. Effect of dietary composition on fasting-induced changes in serum thyroid hormones and thyrotropin. Metabolism 1978; 27(8):935-42. doi:10.1016/00260495(78)90137-3.

25. Sajid KM, Akhtar M, Malik GQ. Ramadan fasting and thyroid hormone profile. J Pak Med Assoc 1991; 41(9): 213-6.

26. Takruri HR. Effect of fasting in Ramadan on body weight. Saudi Medical Journal 1989; 10(6): 491-4.

27. Klocker N, Belkhadir J, El Ghomari H, Mikou A, Naciri M, Sabri M, eds. Effects of extreme chrono-biological diet alternations during Ramadan on metabolism in NIDDM diabetes with oral treatment. Proceeding of the 2nd International Congress on Health and Ramadan, 1997.

28. Rashed AH. The fast of Ramadan: No problems for the well: The sick should avoid fasting. Br Med J 1992; 304(6826): 521-3. 
29. Laajam M. Ramadan fasting and non-insulin-dependent diabetes: effect on metabolic control. East Afr Med J 1990; 67(10): 732-6.

30. Mafauzy M, Mohammed W, Anum M, Zulkifli A, Ruhani A. A study of the fasting diabetic patients during the month of Ramadan. Med J Malaysia 1990; 45(1): 14-7.

31. Sahin SB, Ayaz T, Ozyurt N, Ilkkilic K, Kirvar A, Sezgin $\mathrm{H}$. The impact of fasting during Ramadan on the glycemic control of patients with type 2 diabetes mellitus. Exp Clin Endocrinol Diabetes 2013; 121(9): 531-4. doi:10.1055/s0033-1347247.

32. Sola D, Rossi L, Schianca GPC, et al. Sulfonylureas and their use in clinical practice. Arch Med Sci 2015; 11(4): 840 .

33. Rendell $\mathrm{M}$. The role of sulphonylureas in the management of type 2 diabetes mellitus. Drugs 2004; 64(12): 1339-58. 